\title{
Serum High Sensitivity-C-reactive Protein and Hs-CRP/albumin Ratio in Workers Exposed to Lead from Lead-battery Manufacturing Process
}

\author{
${ }^{1}$ Ravibabu Kalahasthi, ${ }^{2}$ Tapu Barman
}

\begin{abstract}
Purpose: The present study assessed the serum high sensitivity-C-reactive protein (Hs-CRP) and Hs-CRP/albumin ratio of workers exposed to lead $(\mathrm{Pb})$ from $\mathrm{Pb}$-battery manufacturing process with the use of center for disease control and prevention (CDC)/american hospital association (AHA) recommended risk categories of serum Hs-CRP and receiver operating characteristic curve (ROC) to examine the diagnostic accuracy.
\end{abstract}

Materials and methods: This study involved a total of 256 subjects, including both study and control. The study group consists of 176 workers involved in $\mathrm{Pb}$-battery manufacturing process. Control group consists of 80 office workers with no occupational exposure to $\mathrm{Pb}$. Blood lead levels (BLLs) in the study and control groups were determined with atomic absorption spectrophotometer. Serum Hs-CRP concentration was determined using the latex turbidimetric immunoassay method. Serum albumin concentration was measured by using the bromo-cresol green (BCG) method. The serum Hs-CRP/albumin ratio was calculated by dividing the serum Hs-CRP by the serum albumin. Analysis of data was done by using statistical package for the social sciences (SPSS), version 20.0 .

Results: The mean levels of serum Hs-CRP and Hs-CRP/ albumin ratio were shown significantly higher in the study group than in the control group. The abnormal frequency distribution of serum Hs-CRP and Hs-CRP/albumin ratio among study group found significantly higher than in control. Spearmen correlation coefficients ( $r$ ) was found a positive and significant association between BLLs and serum Hs-CRP $(r=0.190)$ and Hs-CRP/albumin ratio $(r=0.193)$. Area under the curve (AUC) of ROC values among the study group noted as $0.465(95 \%$ of $\mathrm{Cl}=0.393-0.537, \mathrm{p}=0.366)$ for serum albumin, $0.601(95 \%$ of $\mathrm{Cl}=0.526-0.675, p=0.010)$ for serum Hs-CRP and $0.598(95 \%$ of $\mathrm{Cl}=0.524-0.672, \mathrm{P}=0.012)$ for $\mathrm{Hs}-\mathrm{CRP} /$ albumin ratio.

Conclusion: The levels of $\mathrm{Hs}-\mathrm{CRP}$ and $\mathrm{Hs}-\mathrm{CRP} /$ albumin ratio were significantly increased in the study group as compared to the control and reduction of $\mathrm{Pb}$-exposure is needed to avoid the risk of cardiovascular disease (CVD) and atherosclerosis.

\footnotetext{
${ }^{1}$ Scientist, ${ }^{2}$ Technical Assistant

1,2Department of Biochemistry, Regional Occupational Health Centre (Southern), Bengaluru, Karnataka, India

Corresponding Author: Ravibabu Kalahasthi, Scientist-C, Department of Biochemistry, Regional Occupational Health Centre (Southern), Bengaluru, Karnataka, India, Phone: +910822172500, e-mail: kalahasthi20012002@yahoo.co.in
}

Keywords: Blood lead, CDC/AHA risk categories of serum Hs-CRP, Hs-CRP/albumin ratio, Pb-exposure, ROC Curve.

How to cite this article: Kalahasthi R, Barman T. Serum High Sensitivity-C-reactive Protein and Hs-CRP/albumin Ratio in Workers Exposed to Lead from Lead-battery Manufacturing Process. Indian J Med Biochem 2018;22(2):120-125.

Source of support: Nil

Conflict of interest: None

\section{INTRODUCTION}

Lead $(\mathrm{Pb})$ is considered an occupational and environmental hazard. The principal source of $\mathrm{Pb}$-exposure is contaminated water, air, and soil. ${ }^{1}$ Lead can enter the body of workers through inhalation and ingestion. Inhalation is the primary route of exposure in $\mathrm{Pb}$-related occupations. ${ }^{2}$ The presence of elevated BLLs in the body were depended on the absorption and ingestion of $\mathrm{Pb}$-compounds. ${ }^{3} \mathrm{~Pb}$-exposure was associated with increased risk of peripheral artery disease, oxidative stress, inflammation and downregulation of nitric oxide production. These disorders are causing the development of atherosclerosis. ${ }^{4}$ Peters et al. ${ }^{5}$ reported that the $\mathrm{Pb}$-exposure was associated with $\mathrm{CVD}$ in healthy older men through its association with tumor necrosis factor-receptor-2 (TNF-R2). Pb-exposure also associated with micro and astrogliosis by triggering TLR4MyD88-NF-kB signaling cascade and production of proinflammatory cytokines. ${ }^{6}$ A linear association was reported between BLLs and CVD mortality in US adults. ${ }^{7} \mathrm{Xu}$ et al. ${ }^{8}$ reported that the low BLLs was positively associated with low-density lipoprotein-cholesterol (LDL-C), which is called bad cholesterol, rich in cholesterol esters and biomarker for atherosclerosis. Datta et al. ${ }^{9}$ study assessed the serum Hs-CRP and LDL-C in myocardial infarction cases and control, and the results found significantly higher levels of serum Hs-CRP in myocardial infarction cases than in controls, but the LDL-C concentration was unaltered. A recent study of Wang et al. reported that the Hs-CRP concentration was associated with an increased risk of CVD and myocardial infarction. ${ }^{10}$ Authors concluded that the serum Hs-CRP had a better predictive value of assessing the risk of atherosclerosis. Due to the above-stated reasons the present study has chosen the estimation of serum Hs-CRP with serum Hs-CRP/albumin ratio for assess- 
ing the risk of $\mathrm{Pb}$-exposure on $\mathrm{CVD}$ and atherosclerosis. The lower and middle-income countries are facing the public health burden of CVD due to exposure of ambient air pollution, household air pollution, $\mathrm{Pb}$, arsenic (As), and cadmium $(\mathrm{Cd}) .{ }^{11} \mathrm{~Pb}$-exposure played a major role in the genesis of coronary artery diseases, which was evaluated through the measurement of blood pressure, glucose, and serum lipids. ${ }^{12}$

Studies regarding occupational exposure to $\mathrm{Pb}$ have reported sub-clinical inflammation through elevated levels of neutrophil-lymphocyte ratio ${ }^{13}$ atherosclerosis, ${ }^{14}$ inflammation. ${ }^{15}$ Kasperczyk et al. ${ }^{16}$ reported an association between BLLs and positive acute phase proteins (ceruloplasmin and haptoglobin) among workers exposed to $\mathrm{Pb}$ from Zinc-lead work process. Population-based studies have presented no association between BLLs and serum CRP. ${ }^{17,18}$ Sirivarasai et al. ${ }^{19}$ suggested that the $\mathrm{Pb}$ exposure is associated with adverse changes in the inflammatory marker (serum CRP) in environmental exposure. The elevated level of serum Hs-CRP was observed in workers exposed to airborne particulate matter from pulp and paper mill process, ${ }^{20} \mathrm{Zn}$-Cu containing welding fumes, ${ }^{21}$ photocopiers operators, ${ }^{22}$ stone quarry ${ }^{23}$ and ultrafine and fine particulate. ${ }^{24}$

C-reactive protein (CRP) belongs to pentraxin protein family and is synthesized hepatocytes and some extra-hepatic tissues such as vascular smooth muscle, atherosclerotic plaques, and cardiac tissues. The high sensitive C-reactive protein precisely measures a low concentration of CRP to identify low levels of inflammation, which helps to predict a person's risk of developing CVD. It is also recommended for primary and secondary CVD prevention. ${ }^{25}$ On the basis of data obtained from adult population studies the AHA/CDC working group on markers of inflammation in CVD has classified serum Hs-CRP as $<1,1-3$ and $>3 \mathrm{mg} / \mathrm{L}$ as low, intermediate and high risk for global CVD respectively. ${ }^{26}$ Studies on the association between BLLs and serum Hs-CRP with the use of AHA/CDC recommended risk categories and $\mathrm{Hs}-\mathrm{CRP} /$ albumin ratio (biomarker for systemic inflammation and superimposed with malnutrition) among workers exposed to $\mathrm{Pb}$ from $\mathrm{Pb}$-battery manufacturing plant was not attempted. The diagnostic accuracy of serum albumin, serum Hs-CRP, Hs-CRP/albumin ratio with the use area under the curve of ROC among workers exposed to $\mathrm{Pb}$ from $\mathrm{Pb}$-battery plant was not studied. The present study aimed to assess the serum albumin, Hs-CRP and Hs-CRP/albumin ratio of workers exposed to $\mathrm{Pb}$ from $\mathrm{Pb}$-battery manufacturing process with consideration of AHA/CDC recommended risk categories and ROC curve to examine the diagnostic accuracy of inflammatory markers.

\section{MATERIALS AND METHODS}

The study design was a case-control survey. This study involved a total of 256 subjects, including both study and control groups. The study group consists of 176 workers, who were working in Pb-battery manufacturing plant located in Tamil Nadu, India. Control group comprising 80 office workers with no occupational exposure to $\mathrm{Pb}$. The study group was matched with a control group with respect to age, body mass index (BMI), diastolic blood pressure (DBP), systolic blood pressure (SBP) and frequency distribution of alcohol consumption and smoking habits. Lead metal exposed workers employed in $\mathrm{Pb}$ acid battery manufacturing industry were included them as a study group in the current study. Subjects with diabetes and hypertension were excluded from the study. Cases of thyroid disease, chronic obstructive pulmonary diseases (COPD) and asthma were not found in study and control groups in the present study. The institutional ethical committee (IEC) has approved the study. Subjects were informed about the study and consent was obtained before their participation in the study.

The demographic details, occupational health history, and habit of subjects (smoking and alcohol consumption) were collected by using a pre-validated questionnaire. BMI was calculated using subjective weight $(\mathrm{Kg})$ and height $\left(\mathrm{m}^{2}\right)$ and was expressed as $\mathrm{Kg} / \mathrm{m}^{2}$.

\section{Sample Collection}

From each subject, $3 \mathrm{~mL}(2 \mathrm{~mL}$ in heparin tubes $+1 \mathrm{~mL}$ in plain tubes) of the whole blood sample was collected. Two ml of heparinized whole blood sample was used for determination of BLLs. One mL of a whole blood sample collected in a plain tube, centrifuged at 4000 RPM for 10 minutes at $4^{\circ} \mathrm{C}$ for separation of serum. The separated serum was used for the determination of albumin and Hs-CRP.

\section{Blood Lead Levels}

Two ml of venous whole blood was collected in a heparinized VACUETTE® from the study subjects and was stored at $-20^{\circ} \mathrm{C}$ until the analysis. Using ETHOS-D, (Milestone Microwave Laboratory Systems, Sorisole, BG, Italy), 2 $\mathrm{mL}$ of whole blood was digested with $2 \mathrm{~mL}$ of nitric acid $\left(\mathrm{HNO}_{3}\right)$ and $0.2 \mathrm{~mL}$ of hydrogen peroxide $\left(\mathrm{H}_{2} \mathrm{O}_{2}\right)$ while maintaining power, temperature, and duration of the process. The processed samples were made up to $5 \mathrm{~mL}$ using distilled water and centrifuged. The concentration of lead was measured using Atomic Absorption Spectrophotometer (GBC Avanta P, Australia). A standard solution of $20 \mu \mathrm{g} / \mathrm{dL}$ of $\mathrm{Pb}$ was prepared from the stock standard solution obtained from the Merck (1.19776.0500) 
and added to the lowest concentration of the sample. The analysis found $100 \%$ recovery with \% RSD at $<0.5$ for three replicates, and the BLL was expressed as $\mu \mathrm{g} / \mathrm{dL}$.

\section{Serum Hs-CRP}

The serum Hs-CRP concentration was determined using the latex turbidimetric immunoassay method. In this protocol, latex particles coated with purified anti-CRP, when allowed reacting with samples containing CRP agglutinate causing a change in absorbance. The change of absorbance depends on the concentration of CRP and comparing it with a known concentration of the calibrator. The concentration of serum Hs-CRP in the samples was expressed as $\mathrm{mg} / \mathrm{L}$.

\section{Serum Albumin}

The serum albumin concentration was measured by using bromocresol green method. In this method, albumin in a buffered solution reacts with the anionic bromocresol green dye, which gives a green color that was measured at $628 \mathrm{~nm}$. The intensity of the green color was directly proportional to the concentration of albumin present in the sample. The concentration serum albumin in samples was expressed as $\mathrm{g} / \mathrm{dL}$.

\section{Hs-CRP/albumin Ratio}

The Hs-CRP/albumin ratio was calculated by dividing the serum Hs-CRP by the serum albumin level.

\section{Statistical Analysis}

Statistical analysis of data was made by using the SPSS (version 20.0). Data were presented in mean \pm standard deviation and frequency distribution. Student t-test was used to compare the mean of age, BMI, DBP, SBP, BLLs, albumin, Hs-CRP and Hs-CRP/albumin ratio among study and control groups. Chi-square test was used to assess the frequency distribution of alcohol consumption, smoking habits, albumin, Hs-CRP and Hs-CRP/albumin ratio among study and control groups. The spearmen correlation coefficient ( $r$ ) test was used to find out the association between BLLs and albumin, Hs-CRP and Hs-CRP/albumin ratio. ROC curve with an AUC was performed to examine the diagnostic accuracy of serum albumin, Hs-CRP and Hs-CRP/albumin ratio among the study group. The AUC value $<0.5$ is considered as a null hypothesis. The probability of $<0.05$ is considered significant.

\section{RESULTS}

The demographic details of the study and control groups were reported in Table 1 . The mean \pm standard deviation of age, BMI, DBP and SBP among the study group was suitably matched with controls. Frequency distribution of alcohol consumption and smoking habits among the study group was also suitable matched to control. BLL was significantly increased in the study group as compared to control. The mean BLLs in study group found 1.6 times higher than control. The World Health Organization (WHO) permitted $40 \mu \mathrm{g} / \mathrm{dL}$ as a higher limit of BLLs for adults. ${ }^{27}$ The BLLs in the control group found in within the recommended limits.

The mean \pm SD levels of serum albumin, Hs-CRP and Hs-CRP/albumin ratio in study and control groups were presented in Table 2. Serum Hs- CRP and Hs-CRP/ albumin ratio concentrations were presented significantly higher in the study group as compared with the control group.

The distribution of the normal and abnormal proportion of serum albumin, Hs-CRP, and Hs-CRP/Albumin ratio among study and controls are shown in Table 3. Chi-square test was used to a comparison of normal and abnormal

Table 1: Demographic details of study and control subjects

\begin{tabular}{llll}
\hline Variables & Study $(n=176)$ & Control $(80)$ & Probability \\
\hline Age $($ years $)$ & $36.6 \pm 8.0^{\mathrm{a}}$ & $37.4 \pm 10$ & 0.338 \\
BMI $\left(\mathrm{Kg} / \mathrm{m}^{2}\right)$ & $25.7 \pm 3.3$ & $25.3 \pm 3.0$ & 0.337 \\
\hline Smoking & $138(78)^{\mathrm{b}}$ & $61(76)$ & 0.747 \\
Yes & $38(22)$ & $19(24)$ & \\
No & & & 0.500 \\
\hline Alcohol consumption & $81(46)$ & $41(51)$ & 0.878 \\
Yes & $95(54)$ & $39(49)$ & 0.064 \\
No & $128 \pm 15$ & $127 \pm 19$ & 0.000 \\
\hline Systolic BP $(\mathrm{mm} \mathrm{Hg})$ & $78 \pm 11$ & $75 \pm 13$ & \\
Diastolic BP $(\mathrm{mm} \mathrm{hg)}$ & $32 \pm 12^{* *}$ & $20 \pm 6$ & \\
Blood lead levels $(\mu \mathrm{g} / \mathrm{dL})$ & & & \\
A $=$ Mean \pm standard deviation & & & \\
B $=$ Number of subjects and percentage & & & \\
$*$ * $<0.001$ & & & \\
\hline
\end{tabular}


Table 2: Levels of Hs-CRP and Hs-CRP/albumin ratio in study and control subjects

\begin{tabular}{llll}
\hline Variables & Study $(n=176)$ & Control $(80)$ & Probability \\
\hline Serum albumin $(\mathrm{g} / \mathrm{dL})$ & $4.1 \pm 0.6$ & $4.1 \pm 0.4$ & 0.847 \\
Serum Hs-CRP $(\mathrm{mg} / \mathrm{L})$ & $3.77 \pm 3.5^{*}$ & $2.76 \pm 2.5$ & 0.020 \\
Serum Hs-CRP/albumin ratio & $0.93 \pm 0.8^{*}$ & $0.68 \pm 0.63$ & 0.024 \\
\hline
\end{tabular}
${ }^{*} \mathrm{p}<0.05$

Table 3: Distribution of abnormal frequency of high sensitivity CRP and Hs-CRP/albumin ratio in study and control subjects

\begin{tabular}{llll}
\hline Variables & Study $(n=176)$ & Control (80) & Probability \\
\hline Serum albumin $(\mathrm{g} / \mathrm{dL})$ & & & \\
$\leq 3.5$ & 20 & 5 & 0.259 \\
$>3.5$ & 156 & 75 & \\
\hline Serum Hs-CRP $(\mathrm{mg} / \mathrm{L})$ & & & \\
$<1$ (low risk) & 28 & 23 & $0.012^{*}$ \\
$1-3$ (Average risk) & 62 & 32 & \\
$>3$ (high risk) & 86 & 25 & $0.008^{*}$ \\
\hline Serum Hs-CRP/albumin ratio & & & \\
$<0.43$ & 57 & 40 & \\
$>0.43$ & 119 & 40 &
\end{tabular}

Table 4: Correlation coefficients between blood lead levels and hs-CRP and Hs-CRP/albumin ratio in subjects

\begin{tabular}{lllll}
\hline Variables & BLL $(\mu \mathrm{g} / \mathrm{dL})$ & Albumin $(\mathrm{g} / \mathrm{dL})$ & Hs-CRP $(\mathrm{mg} / \mathrm{L})$ & Hs-CRP/alb ratio \\
\hline Blood lead levels $(\mu \mathrm{g} / \mathrm{dL})$ & 1.000 & - & - & - \\
Serum albumin $(\mathrm{g} / \mathrm{dL})$ & 0.004 & - & - & - \\
Serum Hs-CRP $(\mathrm{mg} / \mathrm{L})$ & $0.193^{*}$ & -0.057 & - & - \\
Serum Hs-CRP/albumin ratio & $0.190^{*}$ & $-0.175^{*}$ & $0.991^{* *}$ & 1.000 \\
\hline
\end{tabular}

${ }^{*}$ Correlation coefficient significant at $p<0.05$

${ }^{* *}$ Correlation coefficient significant at $\mathrm{p}<0.01$

proportion between the groups. The cutoff value used for serum albumin was 5 th percentile of the control group. $\mathrm{CDC} / \mathrm{AHA}$ was recommended risk categories were used for serum Hs-CRP. The median value of control group was used as cut off value for Hs-CRP/albumin ratio The abnormal frequency distribution of serum Hs-CRP and Hs-CRP/albumin ratio was significantly high in the study group as compared with control group.

The results of spearmen correlation coefficients ( $\mathrm{r}$ ) between BLLs and serum albumin, Hs-CRP and Hs-CRP / albumin ratio among subjects were presented in Table 4 . A positive and significant association was shown between BLLs and markers of inflammation such as serum Hs-CRP $(r=0.190)$ and Hs-CRP/albumin ratio $(r=0.193)$. Similarly, a negative association was noted between serum albumin and Hs-CRP ( $\mathrm{r}=-0.057)$ and Hs-CRP/albumin ratio $(r=-0.175)$ and a significant association was noted only in serum albumin and Hs-CRP/albumin ratio. A positive and significant association was presented between Hs-CRP and Hs-CRP/ albumin ratio ( $r=0.991)$.

Receiver operating characteristic (ROC) curves with an equivalent AUC for serum albumin, Hs-CRP, and Hs-CRP/albumin ratio among study group was presented in Figure 1. The present study has used the area

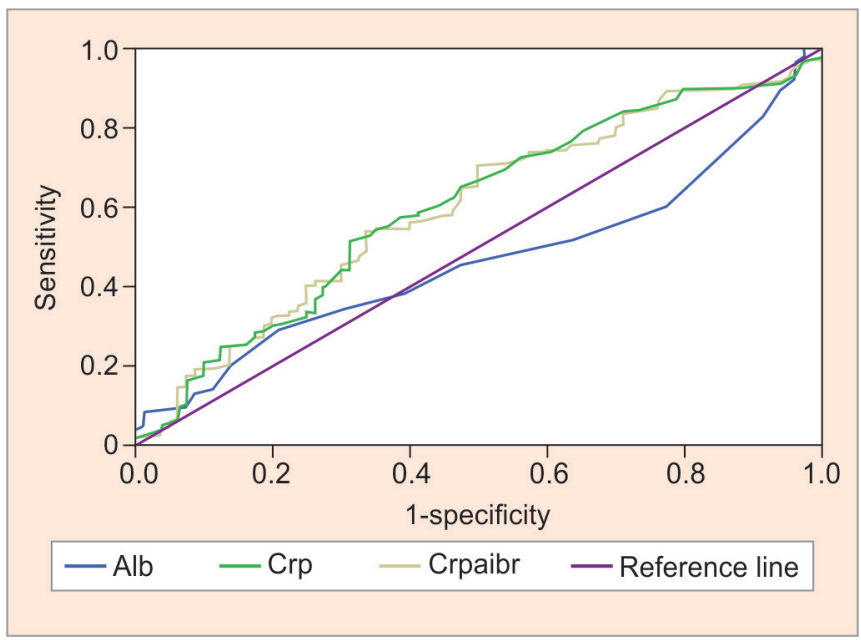

Fig. 1: Receiver operating characteristic curves

with corresponding area under the curve (AUC) for serum albumin, Hs-CRP and Hs-CRP/albumin ratio among study group

under the ROC curve, this parameter can distinguish between two diagnostic groups (disease/normal). It also measures the diagnostic performance of diseased cases from normal cases. The true AUC value $\leq 0.5$ is considered as a null hypothesis. The AUC values reported in this study as 0.465 (95\% of $C I=0.393-0.537$, $\mathrm{p}=0.366)$ for serum albumin, $0.601(95 \%$ of $\mathrm{CI}=0.526-0.675$, 
$\mathrm{p}=0.010)$ for Hs-CRP and 0.598 (95\% of CI $=0.524-0.672$, $\mathrm{p}=0.012)$ for Hs-CRP/albumin ratio. The AUC values of serum Hs-CRP and Hs-CRP/albumin ratio among the study group was found more than 0.5 with significant association with $\mathrm{Pb}$-exposure.

\section{DISCUSSION}

The present study assessed the inflammatory markers such as serum albumin, serum Hs-CRP and Hs-CRP/ albumin ratio among workers exposed to $\mathrm{Pb}$ from $\mathrm{Pb}$ battery manufacturing process. Studies on populationbased have reported no significant association between BLLs and serum Hs-CRP. ${ }^{17,18}$ Peter et al. ${ }^{5}$ reported increased levels of serum Hs-CRP in older men with an increase of BLLs. Sirivarasai et al. ${ }^{19}$ concluded that the $\mathrm{Pb}$-exposure was associated with adverse changes in inflammatory markers. Bal et al. ${ }^{13}$ studied the effect of $\mathrm{Pb}$-exposure on serum $\mathrm{CRP}$ in workers from $\mathrm{Pb}$-battery, $\mathrm{Pb}$-recycling, Pb-smelter plants, and welders. The study noted increased serum CRP concentration in moderate (>10-30 $\mu \mathrm{g} / \mathrm{dL})$ and high Pb-exposure (>30 $\mu \mathrm{g} / \mathrm{dL})$ groups as compared to low exposure $(<10 \mu \mathrm{g} / \mathrm{dL})$ group. Prokopowicz et al. ${ }^{14}$ studied the effect of $\mathrm{Pb}$-exposure on the inflammatory marker of serum C-reactive protein in workers and noticed $54 \%$ of differences in most exposure $(>40 \mu \mathrm{g} / \mathrm{dL})$ than in the least exposure $(<25 \mu \mathrm{g} / \mathrm{dL})$ to lead. The authors of the study concluded that $\mathrm{Pb}$-exposure could promote atherosclerosis with, particularly highly exposed individuals. During the present study, we noted significantly higher levels of serum Hs-CRP in the study group than in controls. The association between BLLs and serum Hs-CRP was presented a positive and significant. A similar association was noted in the studies of Bal et al. ${ }^{13}$ and Khan et al. ${ }^{15}$ Most of the studies were reported that the individual with highly $\mathrm{Pb}$-exposure could promote atherosclerosis and adverse changes in inflammatory response. The data of this study confirms that the $\mathrm{Pb}$ exposure has a significant influence on inflammatory response.

The estimation of serum Hs-CRP is associated with the risk of coronary heart disease (CHD), ischemic heart disease (IHD) and cardiovascular mortality in the general population. ${ }^{28}$ The tangent of both, namely serum Hs-CRP to serum albumin ratio (Hs-CRP/albumin) has more value than either alone with regard to making a prediction of prognosis. The higher ratio of $\mathrm{Hs}-\mathrm{CRP} /$ albumin ratio indicates higher residual inflammation with superimposed malnutrition status. ${ }^{29}$ In this study, we evaluated serum Hs-CRP/albumin ratio in study and control group and found significantly higher levels of serum Hs-CRP / albumin ratio in the study group than in controls. Further, the present study also assessed the association between BLLs and Hs-CRP/albumin ratio among subjects and found a positive and significant association between BLLs and Hs-CRP/albumin ratio.

Studies have not assessed the effect of $\mathrm{Pb}$-exposure on serum Hs-CRP with consideration of CDC/AHA recommended risk categories of serum Hs-CRP. The working group of CDC/AHA on inflammatory markers has classified serum Hs-CRP as $<1,1$ to 3 and $>3 \mathrm{mg} / \mathrm{L}$ as low, intermediate and high risk for global CVD, respectively. ${ }^{26}$ During the present study, the distribution of risk categories of serum Hs-CRP was found significantly increased in $\mathrm{Pb}$ exposed workers than controls. The distribution of serum Hs-CRP/albumin ratio among study and control group was done by using median values of the control group. The levels of serum Hs-CRP/albumin ratio were significantly high in the study group as compared to the control group.

The present study also used the ROC with an AUC to examine the diagnostic accuracy of tests such as serum albumin, Hs-CRP and Hs-CRP/albumin ratio among the study group. AUC values of ROC curve distinguish between two diagnostic groups such as disease and normal. A true AUC value $<0.5$ is considered as a null hypothesis. In the present study, we found AUC value less than 0.5 for serum albumin and more than 0.5 for serum Hs-CRP and serum Hs-CRP ratio among the study group. The AUC values of serum Hs-CRP and serum Hs-CRP ratio were significantly associated with $\mathrm{Pb}$-exposure as compared to controls. The present study limited for the estimation of serum albumin, Hs-CRP and Hs-CRP/ albumin ration among $\mathrm{Pb}$-exposure. Further studies are needed targeting on the estimation of serum albumin, Hs-CRP, Hs-CRP/albumin ratio with lipid profile and other cardiac markers (lipoprotein-associated phospholipase A2 (Lp-PLA2) among Pb-exposure to provide more information about cardiovascular diseases.

\section{CONCLUSION}

The results of this study indicated that the $\mathrm{Pb}$-exposure was significantly altered the inflammatory markers and reduction of $\mathrm{Pb}$-exposure is needed to avoid the risks of atherosclerosis and CVD.

\section{REFERENCES}

1. Abdallah ESH, Badary DM. Folic acid protects against lead acetate-induced hepatotoxicity by decreasing NF- B, IL-1 production and lipid peroxidation mediataed cell injury. Pathophysiology [Internet]. Elsevier BV; 2017 Mar;24(1):39-44.

2. Ibeh N, Aneke J, Okocha C, Okeke C, Nwachukwuma J. The Influence of Occupational Lead Exposure on Haematological Indices among Petrol Station Attendants and Automobile Mechanics in Nnewi, South-East Nigeria. Journal of Environmental and Occupational Science [Internet]. ScopeMed 
International Medical Journal Management and Indexing System; 2016;5(1):1-6.

3. Bagepally B, Kalahasthi R, Barman T. Serum Iron, Zinc and its relationship with Blood lead levels among lead exposed worker from lead battery plant. Journal of Molecular Pathophysiology [Internet]. ScopeMed International Medical Journal Management and Indexing System; 2016;5(3):49.

4. Navas-Acien A, Selvin E, Sharrett AR, Calderon-Aranda E, Silbergeld E, Guallar E. Lead, Cadmium, Smoking, and Increased Risk of Peripheral Arterial Disease. Circulation [Internet]. Ovid Technologies (Wolters Kluwer Health); 2004 Jun 29;109(25):3196-3201.

5. Peters JL, Kubzansky LD, Ikeda A, Fang SC, Sparrow D, Weisskopf MG, et al. Lead Concentrations in Relation to Multiple Biomarkers of Cardiovascular Disease: The Normative Aging Study. Environmental Health Perspectives [Internet]. Environmental Health Perspectives; 2012 Mar;120(3):361-366.

6. Chibowska K, Baranowska-Bosiacka I, Falkowska A, Gutowska I, Goschorska M, Chlubek D. Effect of Lead $(\mathrm{Pb})$ on Inflammatory Processes in the Brain. International Journal of Molecular Sciences [Internet]. MDPI AG; 2016 Dec 19;17(12):2140.

7. Aoki Y, Brody DJ, Flegal KM, Fakhouri THI, Axelrad DA, Parker JD. Blood Lead and Other Metal Biomarkers as Risk Factors for Cardiovascular Disease Mortality. Medicine [Internet]. Ovid Technologies (Wolters Kluwer Health); 2016 Jan;95(1):e2223.

8. Xu C, Shu Y, Fu Z, Hu Y, Mo X. Associations between lead concentrations and cardiovascular risk factors in U.S. adolescents. Scientific Reports [Internet]. Springer Nature; 2017 Aug $22 ; 7(1)$.

9. Datta S, Iqbal Z, Prasad KR. Comparison Between Serum hsCRP and LDL Cholesterol for Search of a Better Predictor for Ischemic Heart Disease. Indian Journal of Clinical Biochemistry [Internet]. Springer Nature; 2011 Jan 19;26(2):210-213.

10. Wang A, Liu J, Li C, Gao J, Li X, Chen S, et al. Cumulative Exposure to High Sensitivity C Reactive Protein Predicts the Risk of Cardiovascular Disease. Journal of the American Heart Association [Internet]. Ovid Technologies (Wolters Kluwer Health); 2017 Oct 11;6(10):e005610.

11. Burroughs Peña MS, Rollins A. Environmental Exposures and Cardiovascular Disease. Cardiology Clinics [Internet]. Elsevier BV; 2017 Feb;35(1):71-86.

12. Sponder M, Fritzer-Szekeres M, Marculescu R, Mittlböck M, Uhl M, Köhler-Vallant B, Strametz-Juranek J. Blood and urine levels of heavy metal pollutants in female and male patients with coronary artery disease. Vascular health and risk management. 2014;10:311.

13. Bal C, Karakulak U, Gunduzoz M, Ercan M, Tutkun E, Yılmaz $\mathrm{OH}$. Evaluation of Subclinical Inflammation with Neutrophil Lymphocyte Ratio in Heavy Metal Exposure. J Clin Anal Med 2016;7(5):643-647.

14. Prokopowicz A, Sobczak A, Szuła-Chraplewska M, Zaciera M, Kurek J, Szołtysek-Bołdys I. Effect of occupational exposure to lead on new risk factors for cardiovascular diseases. Occup Environ Med. 2017 May 1;74(5):366-373.

15. Khan D, Qayyum S, Saleem S, Khan F. Lead-induced oxidative stress adversely affects health of the occupational workers. Toxicology and Industrial Health [Internet]. SAGE Publications; 2008 Oct;24(9):611-618.

16. Kasperczyk A, Prokopowicz A, Dobrakowski M, Pawlas N, Kasperczyk S. The Effect of Occupational Lead Exposure on
Blood Levels of Zinc, Iron, Copper, Selenium and Related Proteins. Biological Trace Element Research [Internet]. Springer Nature; 2012 Aug 26;150(1-3):49-55.

17. Pollack AZ, Mumford SL, Sjaarda L, Perkins NJ, Malik F, Wactawski-Wende J, Schisterman EF. Blood lead, cadmium and mercury in relation to homocysteine and C-reactive protein in women of reproductive age: a panel study. Environmental Health. 2017 Dec;16(1):84.

18. Songdej N, Winters PC, McCabe MJ, Wijngaarden E van. A population-based assessment of blood lead levels in relation to inflammation. Environmental Research [Internet]. Elsevier BV; 2010 Apr;110(3):272-277.

19. Sirivarasai J, Wananukul W, Kaojarern S, Chanprasertyothin S, Thongmung N, Ratanachaiwong W, et al. Association between inflammatory marker, environmental lead exposure, and glutathione S-transferase gene. Biomed Res Int. 2013;2013:474963.

20. Westberg H, Elihn K, Andersson E, Persson B, Andersson L, Bryngelsson I-L, et al. Inflammatory markers and exposure to airborne particles among workers in a Swedish pulp and paper mill. International Archives of Occupational and Environmental Health [Internet]. Springer Nature; 2016;89:813-822.

21. Markert A, Baumann R, Gerhards B, Gube M, Kossack V, Kraus T, et al. Single and Combined Exposure to Zinc- and Copper-Containing Welding Fumes Lead to Asymptomatic Systemic Inflammation. Journal of Occupational and Environmental Medicine [Internet]. Ovid Technologies (Wolters Kluwer Health); 2016 Feb;58(2):127-132.

22. Elango N, Kasi V, Vembhu B, Poornima JG. Chronic exposure to emissions from photocopiers in copy shops causes oxidative stress and systematic inflammation among photocopier operators in India. Environmental Health [Internet]. Springer Nature; 2013 Sep 11;12(1):78.

23. Mehere BA, Patil MB, Pingle SK, Thakkar LR, Butle AB. Determination of levels of C-Reactive Protein (CRP) and Liver function test parameters among occupationally exposed stone quarry workers of Central India: A quest in pursuit of Biomarkers of occupational diseases of stone quarries. Bull. Env. Pharmacol. Life Sci. 2016 May 6;5:33-38.

24. Hertel S, Viehmann A, Moebus S, Mann K, Bröcker-Preuss M, Möhlenkamp S, et al. Influence of short-term exposure to ultrafine and fine particles on systemic inflammation. European Journal of Epidemiology [Internet]. Springer Nature; 2010 Jun 18;25(8):581-592.

25. Adukauskien D, iginskien A, Adukauskait A, Pentiokinien D, Šlapikas R, eponien I. Clinical relevance of high sensitivity C-reactive protein in cardiology. Medicina [Internet]. MDPI AG; 2016;52(1):1-10.

26. Pais $P$, Kamath D, Xavier D, Sigamani A. High sensitivity C-reactive protein (hsCRP) and cardiovascular disease: An Indian perspective. Indian Journal of Medical Research [Internet]. Medknow; 2015;142(3):261.

27. World Health Organization. Recommended health-based limits in occupational exposure to heavy metals. Report of a WHO Study Group. Geneva, Switzerland; 1980.

28. Chandrashekara S. C-reactive protein: An inflammatory marker with specific role in physiology, pathology, and diagnosis. Internet Journal of Rheumatology and Clinical Immunology. 2014 Oct 30;2(S1).

29. Hwang JC, Jiang MY, Lu YH, Wang CT. Precedent fluctuation of serum hs-CRP to albumin ratios and mortality risk of clinically stable hemodialysis patients. PloS one. 2015 Mar 20;10(3):e0120266. 